\title{
Multi-Channel Shopping Behavior of Consumers: Fashion and Design Industry of Pakistan
}

\author{
NADIA IQBAL \\ Ph.D. Scholar (Iqra University Islamabad Campus) \\ Email: Nadiaiqbal2@yahoo.com
}

\begin{abstract}
Consumer behavior has undergone transformational changes because of whole range of new products, changing lifestyles, advancements in communication technologies, readily available information, and multiple shopping channels. Specifically, consumers of contemporary era want a shopping ecosystem where they have consistent interaction with brands across multiple channels. However, Despite the benefits that multichannel shopping provides to consumers and the increased availability of products on various channels, multichannel shopping has not yet received widespread acceptance. One of the reasons is consumer's different perceptions for accepting new technology. Thus, the purpose of current study is to identify the technology acceptance drivers that influence multichannel shopping behavior of consumers. To this end "Unified theory of acceptance and use of technology extended (UTAUT2)", has been applied. Moreover, UTAUT2 model is modified by an additional variable of perceived risk and its effect has been investigated. Descriptive statistics, reliability, and confirmatory factor analysis was examined through SPSS statistical package, while Amos 22.0 was used for the "Structural Equation Modelling (SEM)".

Keywords: Technology Adoption, Multichannel Shopping, Perceived Risk, Facilitating Condition, Social Influence, and Effort Expectancy.

\section{Introduction}

Increasing digitalization and the advent of the internet has transformed the whole shopping process and experience during the last two decades. Shopping has become an exclusive experience independent of time or location. The latest technology has made it possible for the consumers to search for and buy the product using a variety of shopping channels literally at any time and from anywhere. (Verhoef, Neslin, \& Vroomen, 2007). The increasing role of these channels in both offline as well as online retailing has made it imperative for the retailers to focus on every phase of shopping process and provide the consumers with precise sources of information. Retail businesses continue to experience changes because of the penetration of different platforms like smart phones, social media, and tablets into the society. Specifically, the new shopper of Pakistan shows high level of interest in new technology and emerging nontraditional platforms for shopping.

The purchase intention of consumers is arguably being driven by new technologies such as $3 \mathrm{G} \& 4 \mathrm{G}$, Smart phones, mobile apps etc. New technology has changed shopping pattern of consumers specifically in textile sector. These contemporary shoppers want flexible shopping experience by exploring various online and offline channels. The needs of the consumers have become of so varied kind and nature that the fashion retailers must provide them with multiple channels and innovative, sometimes customized, ways to cater to the changing requirements. However fashion retail market is still unable to cope up with changing consumer needs (Sramova \& Pavelka, 2019).
\end{abstract}


Despite the benefits that multichannel shopping provides to consumers and the increased availability of products on various channels, multichannel shopping has not yet received widespread acceptance (Herhausen, Binder, Schoegel, \& Herrmann, 2015). One of the reasons is consumer's different perceptions for accepting new technology. To understand consumers behavior and acceptance of new technology various theoretical models have been studied (Bagozzi, 2007). However, most of the researches related to multichannel shopping lack integration of latest theories (Liang, Ho, Li, \& Turban, 2011). The current study incorporates "Unified theory of acceptance and use of technology extended (UTAUT2)", which had outperformed all preceding models of technology acceptance (Venkatesh, Thong, \& Xu, 2012). UTAUT2 pays special consideration to the use of technology devices, applications, and services in consumer context, which is an emerging and highly demanding industry (Stofega \& Llamas, 2009). The application of UTAUT2 helps to understand the important phenomena of multichannel shopping behavior of consumers by studying factors that lead them towards the acceptance and use of technology for shopping of fashion clothing items. Thus current study deems to recognize the factors that influence multichannel shopping behaviour of consumer. To this end a model is presented to gain insight into the multichannel shopping behaviour based on the variables used in the unified theory of technology acceptance extended UTAUT2 model. Furthermore, based on the review of extant literature UTAUT 2 model is extended by additional variables of perceived risk factor.

\section{Research Objectives}

- The objective of this study is to recognize the factors that influence multichannel shopping behavior of consumer. To this end a model is presented to gain insight into the multichannel shopping behavior based on the variables (Effort expectancy, Performance expectancy, Social influence, Behavioral intention, Actual usage) used in the unified theory of technology acceptance extended UTAUT2 model.

- Moreover, the uncertainties related to the use of multiple channels are studied by additional variable of perceived risk.

- Current study enables fashion and designing industry of Pakistan to understand modern consumer's way of interaction with offline and online retail channels.

\section{Literature Review}

The framework of current research is based on the extended Unified Theory of Acceptance and Use of Technology (UTAUT2) model (Venkatesh et al., 2012) that seeks to identify the drivers of technology acceptance and use during the multichannel shopping expedition of consumer. More specifically current study investigates impact of performance expectancy (PE), effort expectancy (EE), social influence (SI), on behavioral intention (BI) and actual use (USE). Moreover, an additional construct perceived risk (PR) was studied to analyze underlying factors that refrain consumers from the use of multichannel shopping.

\section{Performance Expectancy (PE)}

Consumer expectations regarding the benefits in return of engaging in different activities using technology is called performance expectancy (Venkatesh et al., 2012). The extent to which consumers expect the benefits in return of engaging in different activities using technology is called performance expectancy. In the light of previous literature performance expectancy has been conceived from outcome expectations, perceived usefulness, extrinsic motivation, and relative advantage (Escobar-Rodríguez \& Carvajal-Trujillo, 2014).

Users of multichannel platforms for shopping certainly benefit tremendously from flexibility of time, increased convenience. Comparing products, assessing their relevant information, choosing preferred platform to purchase etc. saves precious time which in turn compels consumers to opt for multichannel shopping instead of the old orthodox way. Thus, in multichannel shopping context consumers expect 
external rewards in the form of different deals, discounts, and promotions on new products. Multiple channels provide consumers with enough information to analyze products and buy the one at less cost and with more benefits. Moreover, previous studies consider (PE) as a strong determinant of purchase intention (Pascual-Miguel, Agudo-Peregrina, \& Chaparro-Peláez, 2015). Thus, this study strives to propose the following hypothesis:

H1: Performance expectancy positively influence behavioral intention (BI) to use multichannel shopping.

\section{Effort Expectancy (EE)}

Ease of use associated with the use of technology is defined as effort expectancy. Consequently, in multichannel shopping context 'ease of use' is conceptualized as the consumer's ability to use different channels effortlessly and with minimum level of complexity. On the basis of previous literature, the construct of effort expectancy has been derived from three concepts; complexity, perceived ease of use and 'ease of use' (Venkatesh et al., 2012).

Thus if a user deems it easy to use technology for the purpose of conducting an activity than it portrays their ease of use as well as their acceptance. For technology Therefore, in the realm of multichannel shopping, ease of use is assumed as the consumer's capability to use these diverse channels smoothly and with minimum level of complication. As a result, effort expectancy becomes significant for consumers who think of fashion shopping as a problem-solving challenge.

Thus, current study suggest that effort expectancy becomes important for consumers thinking of fashion shopping as a problem solving endeavor (Bellenger, 1980). Thus, this study proposes:

H2: Effort expectancy positively influences behavioral intention (BI) to use multichannel shopping.

\section{Social Influence (SI)}

Perception of significant ones (e.g., close friends, family members) about the use of certain technology is defined as social influence (Van der Heijden, Verhagen, \& Creemers, 2003). In other words, social influence means the perception of important others (e.g., close friends, family members) about the use of certain technology. Similar constructs can also be found in other technology acceptance models as 'motivation to conform', "subjective norms" or "social factors". According to (Chandon, Wansink, \& Laurent, 2000), while making shopping decisions social influence refers to the extent of help or opinion consumer needs from significant others. Being a basic constituent of self-expression, 'motivation to conform' forms a hedonic benefit to consumers (Ailawadi \& Harlam, 2002).

According to (Nicholson, Clarke, \& Blakemore, 2002) shopping with friends or family play a vital part in the selection of channels. Many researchers have found that social influence positively influence purchase intention of consumers. Therefore, the following hypothesis was proposed:

H3: Social influence positively influence behavioral intention (BI) to use multichannel shopping.

\section{Perceived Risk (PR)}

Perceived risk is consumer's sensitivity regarding the potentially negative consequences of purchase (Rousseau, Sitkin, Burt, \& Camerer, 1998). Perceived risk is described as the undefined and the potential opposing consequences during the course of a shopping procedure. It has been found to affect the customer's choice of shopping channels. According to (Kazancoglu \& Aydin, 2018) innovative nature of multichannel shopping makes it more risky and unpredictable for consumers. According to previous studies, perceived risk significantly influences individuals' adoption of innovations in numerous 
frameworks such as online banking, mobile payments and in some other similar contexts (Alalwan, Dwivedi, Rana, \& Algharabat, 2018) (Alalwan et al., 2018) (Tseng \& Wang, 2016). Consequently, it is expected that undefined situations such as unpredictable price, products, and services across channels will surge perceived risk. Nevertheless, multichannel e-trailers are associated with lower risk perceptions compared to higher risk perceptions involved in single channel e-trailers. Reliability, trustworthiness, reputed brand name and lucrative exchange and return policy of multichannel e-trailers might be the reason behind lower perceived risks of consumers while purchasing from their online channels. Consumers that are not afraid of taking risks often choose non-store options of multichannel retailers. Consumers, however, often feel uncertain about relatively novel multichannel shopping, and are often repelled by the ambiguity of the purchase process which keeps them from actually buying a product even after visiting multiple channels (Forsythe \& Shi, 2003). thus current study suggests that in order to make multi channeling shopping experience to be a success it is vital for the consumers to perceive it as a low risk venture. This would not only render their outlook to be more positive towards using this platform but also encourage more reliance on the use of multiple channels. However, certain factors such as uncertainty of channel transition and the overall unease about innovative technology contribute towards little acceptance and perception of risks. On the basis of this, the current study suggests that the engagement of consumers across multiple channels is affected negatively by the risk perception of consumers.

H9: Perceived risk negatively influence BI to use multichannel shopping.

\section{Behavioral intention and Use}

Behavioral intention(BI) is Inclination of a user towards the use of a system or technology (Davis, 1989). Majority of the researchers agree that the intention of a consumer to use a technology strongly determines and predicts whether the user will actually use a technology and will keep on using it later on as well. Behavioral intention has hence been used in technology acceptance models as a central concept (Taylor \& Todd, 1995).

H10: Behavioral intention will have a significant positive influence on Multichannel shopping.

\section{Data Analysis}

\section{Research Design}

This study adopted cross-sectional approach to test hypothetical framework. The target population of the study was multichannel consumers who buy fashion clothing items from brands having both online and offline presence. The sampling technique used for current study was convenience sampling method. This research method is the very common among the researchers of behavioral sciences. Researcher can select individual from large population on the basis of accessibility and willingness of the respondent. (Roscoe, 1975) consider sample size greater than 30 or less than 500 adequate for most research. Additionally, structural equation modelling requires comparatively large sample size for better results, where sample size greater than 400 is appropriate for a model having 6 variables (Kline, 2010). Thus 700 questionnaires were distributed among individuals, where 460 questionnaires were received while 435 questionnaires were usable. Thus $62.14 \%$ of questionnaires comprises of usable data for further analysis. Before conducting analysis, data screening was done for the identification of outliers, and missing data. For the treatment of missing data widely accepted method, missing completely at random (MCAR) was applied. However, because of the strict criteria for the selection of respondents, no missing values were observed. For the detection of multivariate outliers Mahalanobis D2 method was applied. Only 3 out of 435 values were identified as multivariate outliers who were quite ignorable. Additionally, QQ-Plots of each construct indicated linear pattern of observations and ruled out the possibility of non-linearity. Measures: 
As current study is an application of UTAUT2, thus most of the items are adapted from (Venkatesh et al., 2012). All items were measured on five-point Likert-type, where 1 stands for "Strongly disagree" and 5 stands for "Strongly Agree". Where 1st three questions determine multichannel shopping behavior of consumers. The respondents who didn't fulfil the criteria of multichannel consumers were refrained from further response to questionnaire. The items of "Performance Expectancy, Effort expectancy, and Behavior Intention" were adapted from (Van der Heijden et al., 2003). Perceive risk was adapted from (Van der Heijden et al., 2003). The scale of the Multichannel Usage was adapted from (Yu, Niehm, \& Russell, 2011).

Current study utilized "Structural equation modeling (SEM)", to assess proposed model. Primarily a "confirmatory factor analysis CFA", was conducted to assess validity and reliability of the constructs. Later on, "covariance based Structural equation model (CBSEM)", using Amos 22.0 was demonstrated to assess hypothesized relationships. For descriptive analysis SPSS was used. First data normality was inspected by checking values of skewness and kurtosis of all the scale items. The results indicate that negative and positive skewness values lie between the range of -1.13 to -0.322 and 0.316 to 0.105 respectively. While the positive and negative kurtosis values lie between the range of -0.683 to -0.136 and 1.81 to 0.268 respectively. Above findings indicate that the data were normally distributed. For the assessment of multicollinearity VIF values of all exogenous variables were measured along with the tolerance level. The results fulfill the criteria defined by (Hair, Black, Babin, Anderson, \& Tatham, 2006) because all VIF scores lie between 1.03 to 1.36 and tolerance values fulfill the minimum threshold value. Thus, results show that multicollinearity issue doesn't exist among the exogenous variables.

The Mean and SD of all respondents is exhibited in Table 1. The findings of descriptive analysis show that the mean of all constructs is greater than 3 . Thus, indicating that most of the respondents exhibited positive response towards the constructs of proposed model. The value of SD is low and ranges from 0.529 to 1.046.

Table 1 Descriptive statistics:

\begin{tabular}{|lll|}
\hline Constructs & Mean & S.D \\
\hline EE & 3.465 & .932 \\
BI & 3.495 & .615 \\
PR & 3.237 & .851 \\
PE & 3.315 & .838 \\
USE & 3.188 & .945 \\
SI & 3.617 & 1.046 \\
\hline
\end{tabular}

\section{Assessment of Reliability of Data}

For the determination of reliability and internal consistency of the constructs Cronbach's alpha was calculated. As Table 2 results indicate that the value of Cronbach's alpha for most of the construct was above 0.7 . Results indicate good reliability and internal consistency of the items.

Table 2: Reliability Test

\begin{tabular}{|c|c|c|}
\hline Constructs & Number of items & Cronbach's Alpha Coefficient \\
\hline PE & 4 & 0.870 \\
\hline EE & 3 & 0.712 \\
\hline SI & 3 & 0.996 \\
\hline PR & 3 & 0.993 \\
\hline BI & 3 & 0.942 \\
\hline USE & 4 & 0.719 \\
\hline Total & 20 & \\
\hline
\end{tabular}


As results of Table 3 revealed that the composite reliability (CR) of constructs is above 0.7 and average variance extracted (AVE) values are higher than the minimum acceptable value of 0.5 . After establishment of convergent validity discriminant validity was measured on the basis of correlation of items and covariance difference among the factors. The diagonal values of correlation matrix show square root of AVE while off diagonal values show corresponding correlation coefficients of factors. As table 3 Shows that the square root of AVE is higher than the inter-scale correlation. Additionally, none of the latent variable coefficient values are above 0.5 , thus discriminant validity was established.

Table 3: Discriminant Validity

\begin{tabular}{|c|c|c|c|c|c|c|c|c|}
\hline & CR & AVE & BI & EE & PE & USE & Social & Usage \\
\hline BI & 0.948 & 0.861 & $\mathbf{0 . 9 2 8}$ & & & & & \\
\hline EE & 0.869 & 0.691 & 0.538 & $\mathbf{0 . 8 3 1}$ & & & & \\
\hline PE & 0.857 & 0.608 & 0.109 & -0.053 & $\mathbf{0 . 7 8 0}$ & & & \\
\hline PR & 0.992 & 0.969 & -0.042 & 0.064 & 0.159 & $\mathbf{0 . 9 8 5}$ & & \\
\hline SI & 0.996 & 0.989 & 0.063 & -0.002 & -0.050 & 0.036 & $\mathbf{0 . 9 9 4}$ & \\
\hline USE & 0.997 & 0.990 & 0.407 & 0.413 & 0.025 & -0.011 & -0.051 & $\mathbf{0 . 9 9 5}$ \\
\hline
\end{tabular}

\section{Assessment of Structural Equation Model}

To investigate the direct effects between endogenous and exogenous variables of proposed theoretical framework "Structural Equation Modelling", SEM was conducted. In order to measure the goodness-of-fit for model. The results of Table 4 show that model exhibits good fitness indices and all values are above the minimum acceptance criteria.

Table: 4 Model fit indices:

\begin{tabular}{|lcc|}
\hline Fitness index & Preferred value & Result \\
\hline & & \\
CMIN/DF & $<3$ & 2.397 \\
GFI & $>0.9$ & 0.992 \\
AGFI & $>0.9$ & 0.924 \\
RMR & $<0.05$ & 0.019 \\
NFI & $>0.9$ & 0.97 \\
IFI & $>0.9$ & 0.987 \\
CFI & $>0.9$ & 0.986 \\
RMSEA & $<0.08$ & 0.031 \\
GFI=Goodness of fit index, AGFI= adjusted goodness of fit index, RMSEA=Root mean square \\
error of approximation, $R M R=$ Root mean square residual, IFI= Incremental fit index, \\
NFI=Normative fit index, CFI= Comparative fit index
\end{tabular}

Path analysis was conducted on the proposed model. Standardized estimated values of direct relationships between exogenous and endogenous variables are shown in Figure 1. Additionally, standardized regression coefficients of variables and their respective measurement items are shown in Amos output file Figure 1. 
Figure- 1: Structural Equation Model for Direct Relationships:

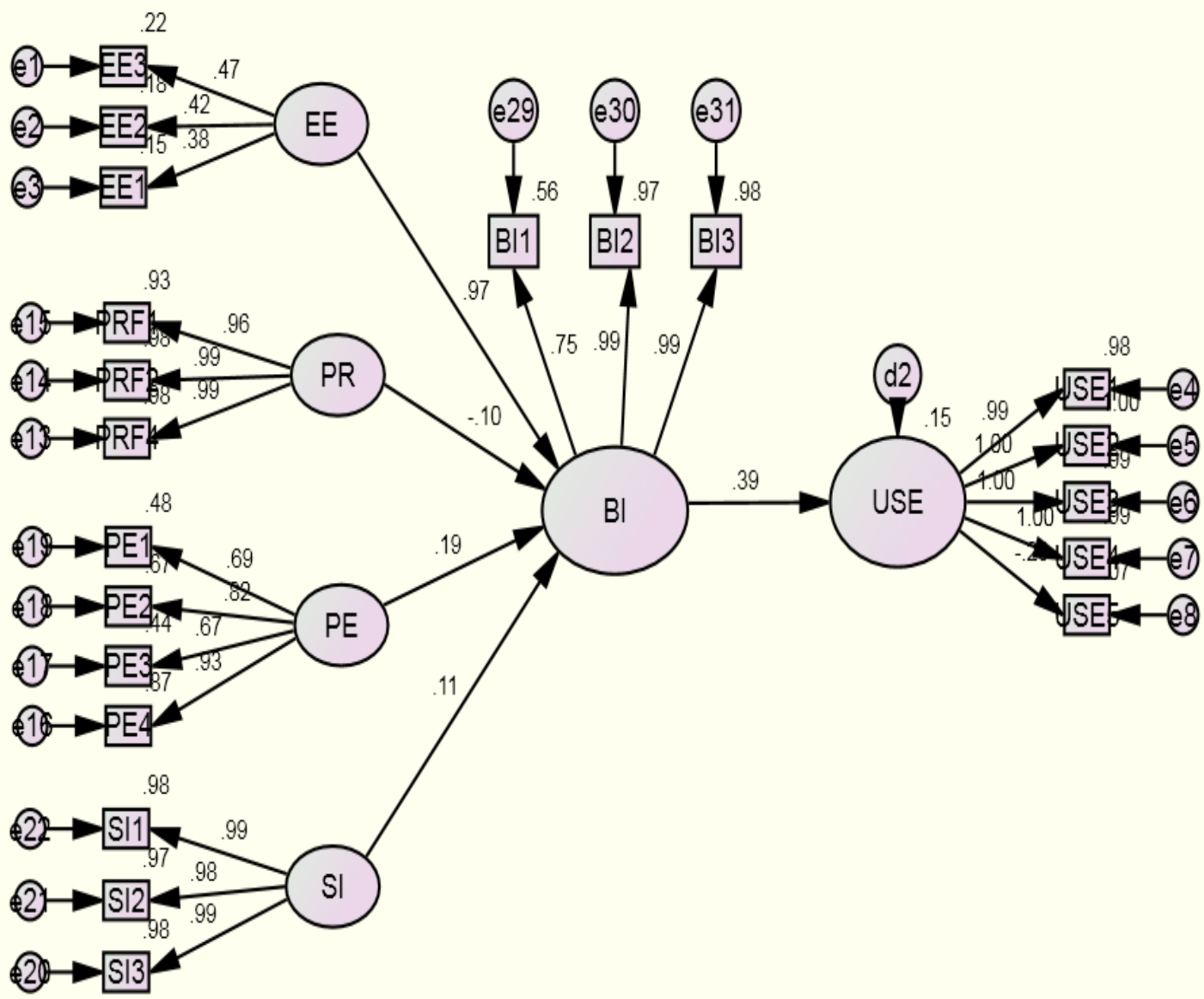

Source: Amos output file

Additionally, Table 5 Show direct relationships among variables. The estimates of regression weights reveal that performance expectancy (PE), effort expectancy (EE), social influence (SI), have a significant and positive effect on behavioral intention (BI). Whereas perceived risk (PR) has negative but significant impact on $\mathrm{BI}$.

Table 5: Hypotheses testing for Direct Relationships

\begin{tabular}{|c|c|c|c|c|c|c|c|}
\hline Hypotheses & \multicolumn{3}{|c|}{ Relationship } & $\begin{array}{l}\text { Standardized } \\
\text { regression } \\
\text { coefficients }(\beta)\end{array}$ & S.E. & C.R. & Results \\
\hline H1 & PE & $\rightarrow$ & BI & 0.186 & .018 & $4.748 * * *$ & Accepted \\
\hline $\mathrm{H} 2$ & $\mathrm{EE}$ & $\rightarrow$ & $\mathrm{BI}$ & 0.971 & .083 & $10.006 * * *$ & Accepted \\
\hline $\mathrm{H} 3$ & SI & $\rightarrow$ & BI & 0.109 & .017 & $2.953 * * *$ & Accepted \\
\hline $\mathrm{H} 4$ & PR & $\rightarrow$ & BI & -0.103 & .017 & $-2.787 * * *$ & Accepted \\
\hline H5 & $\mathrm{BI}$ & $\rightarrow$ & USE & 0.385 & .097 & $8.090 * * *$ & Accepted \\
\hline
\end{tabular}

Standardized path coefficients for all respondents $* * p<0.05 ; * * * p<0.01$. 
As table 5 show that all hypotheses were accepted in the model. Where PE $\left(\beta=0.186^{* * *}\right)$ and $\mathrm{EE}$ $\left(\beta=0.971^{* * *}\right)$ were found to have significant positive impact on the behavioral intention of consumers to use multichannel for shopping of fashion clothing, thus supporting hypotheses $\mathrm{H} 1$ and $\mathrm{H} 2$. The social influence of significant ones on consumers to use various channels for shopping was found to be significant $\left(\beta=0.109^{* * *}\right)$ thus supporting the hypothesis H3. Additionally, results support the negative relationship between perceived risk and behavioral intention of the consumers, thus supporting $\mathrm{H} 4\left(\beta=-0.103^{* *}\right)$. Hypothesis $\mathrm{H} 5$ was also accepted where behavioral intention (BI) has significant and positive impact on actual usage (USE). The variance (R2) in the dataset was measured through Square multiple correlation $(\mathrm{SMC})$. The results indicate that PE, EE, SI, PR account for $58 \%(\mathrm{R} 2=0.58)$ of the variance in BI, with EE being the highest contributing construct. The results show that higher the performance expectancy, effort expectancy, social influence higher will be the behavioral intention of consumers to shop across different channels. Moreover, behavioral intention was found to impact actual behavior of consumers in a positive way.

\section{Discussion}

Our study contributes to existing literature by exploring multichannel shopping behavior of consumers by applying UTAUT2 in consumers use setting. Most of the results of current study were aligned with the "Unified theory of acceptance and use of technology (Ajzen, 1985; Davis, Bagozzi, \& Warshaw, 1989; Morris \& Venkatesh, 2010; Venkatesh et al., 2012[Morris, 2010 \#184). Thus, indicating that multichannel shopping has positive influence on the purchase of fashion clothing items as highlighted in previous studies conducted in fashion retail sector (Blázquez, 2014; Nicholson et al., 2002). The study significantly contributes to the previous literature by studying consumer's multichannel shopping behaviors. Nevertheless, addition of perceived risk in the UTAUT2 model is an important theoretical contribution and revealed imperative findings about consumer's uncertainties about the use of multichannel shopping, where most of the results support previously established hypothesized relationships (Tandon, Kiran, \& Sah, 2016; Wang \& Wang, 2010).

The results indicate that most of the technology acceptance drivers i.e. Effort Expectancy (EE), Performance Expectancy (PE), Social Influence (SI) has significant positive impact on the behavioral intention of consumers. These findings are consistent with the previous studies done in the context of acceptance and use of technology for fashion clothing items (Soni, Jain, \& Kumar, 2019) (Rose, Clark, Samouel, \& Hair, 2012). One of the possible reasons could be that multichannel users are more convenience oriented they want best of both worlds with less efforts and time consumption.

The relationship between $\mathrm{PE} \rightarrow \mathrm{BI}$ was significant, and $\mathrm{H} 1$ was accepted. These findings were aligned with previous studies, where performance expectancy (PE) was considered as a strong determinant of purchase intention (Pascual-Miguel et al., 2015).

Moreover, current study found positive and significant relationship between $\mathrm{EE} \rightarrow \mathrm{BI}$, and $\mathrm{H} 2$ was accepted. The results of the current study found EE as strongest predictor of BI, one of the possible reason could be that consumers want to spend minimum amount of time, energy and mental effort to purchase. Additionally, user friendly mobile apps, easy to use official websites and in-store technology increase behavioral intention of consumers to use fashion items. These findings are consistent with the findings of previous researches and technology acceptance models (Chong, 2013; Venkatesh et al., 2012; Davis et al., 1989). However, these findings were contrary to the findings of (Wei, Marthandan, Chong, Ooi, \& Arumugam, 2009), which found insignificant impact of EE on BI.

The relationship between $\mathrm{PE} \rightarrow \mathrm{BI}$ was significant, and $\mathrm{H} 3$ was accepted. One possible reason could be that consumers can get online opinion of other consumers and experts through various blogs, and social interaction sites. Thus consumers can make their opinion based on the reviews instead of asking relatives and significant others. These findings were consistent with previous studies that consider shopping with 
friends or family play a vital part in the selection of channels (Park, 2009; Teo, 2010). Thus the results of current study found that social influence positively influence purchase intention of consumers to use multiple channels for shopping.

Results of current study revealed a significant but negative relationship between PR and BI, thus supporting Hypothesis H4. Hence it can be inferred from the results that shoppers often feel uncertain about relatively novel multichannel shopping, and can be repelled by the ambiguity of the purchase process which keeps them from actually buying a product even after visiting multiple channels. The inverse relationship of PR and BI found in the results of current study are aligned with previous researches, that suggests that the engagement of consumers across channels can be affected by the risk perception of consumers (Almousa, 2011). Furthermore, current study found positive and significant relationship between BI $\rightarrow$ USE, and H5 was accepted, thus indicating that strong intention of the consumers can lead them towards the actual usage. Its aligned with previous studies, where intention is considered to be the strong predictor of actual behavior. Therefore, consumers having positive intention towards the use of various channels are inclined towards the actual usage of the multiple channels for the shopping of fashion clothing items.

\section{Recommendations/ Future Findings}

Businesses specially fashion clothing retailers are transferring from tradition brick and mortar store to Multichannel but it's just a beginning. Most of the retailers are unable to give flexible shopping experience to consumers, as all channels are working autonomously. Most of the business model lack integration of channels and fail to reach consumers effectively. Specifically, physical stores are deprived of in-store digital technology such as virtual fitting rooms, augmented reality and automatic checkouts. Retailer should take initiative to combine online and in-store retail activities. Such as "ordering in physical store and delivering to home" or "ordering online and return to physical store". Such interactive technologies and innovative steps can blur boundaries between physical and online stores. Thus current study suggests to conduct comparative study between developed and developing countries to evaluate multichannel shopping behavior of consumers from different perspectives.

\section{References}

Ailawadi, K. L., \& Harlam, B. (2002). The effect of store brands on retailer profitability: an empirical analysis. J. Marketing.

Ajzen, I. (1985). From intentions to actions: A theory of planned behavior Action control (pp. 11-39): Springer.

Alalwan, A. A., Dwivedi, Y. K., Rana, N. P., \& Algharabat, R. (2018). Examining factors influencing Jordanian customers' intentions and adoption of internet banking: Extending UTAUT2 with risk. Journal of Retailing and Consumer Services, 40, 125-138.

Almousa, M. (2011). Perceived risk in apparel online shopping: a multi dimensional perspective. Canadian Social Science, 7(2), 23-31.

Bagozzi, R. P. (2007). The legacy of the technology acceptance model and a proposal for a paradigm shift. Journal of the association for information systems, 8(4), 3.

Bellenger, D. N. (1980). Profiling the recreational shopper. Journal of retailing, 56(3), 77-92.

Blázquez, M. (2014). Fashion shopping in multichannel retail: The role of technology in enhancing the customer experience. International journal of electronic commerce, 18(4), 97-116.

Chandon, P., Wansink, B., \& Laurent, G. (2000). A benefit congruency framework of sales promotion effectiveness. Journal of Marketing, 64(4), 65-81.

Davis, F. D. (1989). Perceived usefulness, perceived ease of use, and user acceptance of information technology. MIS quarterly, 319-340.

Davis, F. D., Bagozzi, R. P., \& Warshaw, P. R. (1989). User acceptance of computer technology: a comparison of two theoretical models. Management science, 35(8), 982-1003. 
Escobar-Rodríguez, T., \& Carvajal-Trujillo, E. (2014). Online purchasing tickets for low cost carriers: An application of the unified theory of acceptance and use of technology (UTAUT) model. Tourism Management, 43, 70-88.

Forsythe, S. M., \& Shi, B. (2003). Consumer patronage and risk perceptions in Internet shopping. Journal of Business research, 56(11), 867-875.

Hair, J., Black, W. C., Babin, B. J., Anderson, R. E., \& Tatham, R. (2006). Multivariate Data Analysis: Pearson Education. New Jersey: Hoboken.

Herhausen, D., Binder, J., Schoegel, M., \& Herrmann, A. (2015). Integrating bricks with clicks: retailerlevel and channel-level outcomes of online-offline channel integration. Journal of retailing, 91(2), 309-325.

Kazancoglu, I., \& Aydin, H. (2018). An investigation of consumers' purchase intentions towards omnichannel shopping. International Journal of Retail \& Distribution Management.

Kline, R. B. (2010). Principles and Practice of Structural Equation Modeling, Series Editor's Note by Todd D. Little: New York: The Guilford press.

Liang, T.-P., Ho, Y.-T., Li, Y.-W., \& Turban, E. (2011). What drives social commerce: The role of social support and relationship quality. International journal of electronic commerce, 16(2), 69-90.

Morris, M. G., \& Venkatesh, V. (2010). Job characteristics and job satisfaction: Understanding the role of enterprise resource planning system implementation. MIS quarterly, 143-161.

Nicholson, M., Clarke, I., \& Blakemore, M. (2002). 'One brand, three ways to shop': situational variables and multichannel consumer behaviour. The International Review of Retail, Distribution and Consumer Research, 12(2), 131-148.

Park, S. Y. (2009). An analysis of the technology acceptance model in understanding university students' behavioral intention to use e-learning. Journal of Educational Technology \& Society, 12(3), 150-162.

Pascual-Miguel, F. J., Agudo-Peregrina, Á. F., \& Chaparro-Peláez, J. (2015). Influences of gender and product type on online purchasing. Journal of Business research, 68(7), 1550-1556.

Roscoe, J. T. (1975). Fundamental research statistics for the behavioral sciences [by] John T. Roscoe.

Rose, S., Clark, M., Samouel, P., \& Hair, N. (2012). Online customer experience in e-retailing: an empirical model of antecedents and outcomes. Journal of retailing, 88(2), 308-322.

Rousseau, D. M., Sitkin, S. B., Burt, R. S., \& Camerer, C. (1998). Not so different after all: A crossdiscipline view of trust. Academy of management review, 23(3), 393-404.

Soni, M., Jain, K., \& Kumar, B. (2019). Factors affecting the adoption of fashion mobile shopping applications. Journal of Global Fashion Marketing, 10(4), 358-376.

Sramova, B., \& Pavelka, J. (2019). Gender differences and wellbeing values in adolescent online shopping. International Journal of Retail \& Distribution Management.

Stofega, W., \& Llamas, R. (2009). Worldwide Mobile Phone 2009-2013 Forecast Update, IDC Document Number 217209. Framingham, MA: IDC.

Tandon, U., Kiran, R., \& Sah, A. N. (2016). Understanding online shopping adoption in India: unified theory of acceptance and use of technology 2 (UTAUT2) with perceived risk application. Service Science, 8(4), 420-437.

Taylor, S., \& Todd, P. A. (1995). Understanding information technology usage: A test of competing models. Information systems research, 6(2), 144-176.

Teo, T. (2010). Examining the influence of subjective norm and facilitating conditions on the intention to use technology among pre-service teachers: a structural equation modeling of an extended technology acceptance model. Asia Pacific Education Review, 11(2), 253-262.

Tseng, S.-Y., \& Wang, C.-N. (2016). Perceived risk influence on dual-route information adoption processes on travel websites. Journal of Business research, 69(6), 2289-2296.

Van der Heijden, H., Verhagen, T., \& Creemers, M. (2003). Understanding online purchase intentions: contributions from technology and trust perspectives. European journal of information systems, 12(1), 41-48.

Venkatesh, V., Thong, J. Y., \& Xu, X. (2012). Consumer acceptance and use of information technology: extending the unified theory of acceptance and use of technology. MIS quarterly, 157-178. 
Verhoef, P. C., Neslin, S. A., \& Vroomen, B. (2007). Multichannel customer management: Understanding the research-shopper phenomenon. International journal of research in marketing, 24(2), 129-148.

Wang, H.-Y., \& Wang, S.-H. (2010). User acceptance of mobile internet based on the unified theory of acceptance and use of technology: Investigating the determinants and gender differences. Social Behavior and Personality: an international journal, 38(3), 415-426.

Wei, T. T., Marthandan, G., Chong, A. Y. L., Ooi, K. B., \& Arumugam, S. (2009). What drives Malaysian $\mathrm{m}$-commerce adoption? An empirical analysis. Industrial management \& data systems.

Yu, U.-J., Niehm, L. S., \& Russell, D. W. (2011). Exploring perceived channel price, quality, and value as antecedents of channel choice and usage in multichannel shopping. Journal of Marketing Channels, 18(2), 79-102. 